\title{
Childhood Acute Basophilic Leukemia
}

National Cancer Institute

\section{Source}

National Cancer Institute. Childhood Acute Basophilic Leukemia. NCI Thesaurus. Code

C7971.

An acute basophilic leukemia occurring in children. 